\title{
Commentary
}

\section{Associative facilitation in the Stroop task: Comment on Mahon et al. (2012)}

\author{
Ardi Roelofs* and Vitória Piai \\ Radboud University Nijmegen, Nijmegen, The Netherlands
}

A fundamental issue in psycholinguistics concerns how speakers retrieve intended words from long-term memory. According to a selection by competition account (e.g., Levelt et al., 1999), conceptually driven word retrieval involves the activation of a set of candidate words and a competitive selection of the intended word from this set. Selection by competition explains, for example, the Stroop interference effect (e.g., Roelofs, 2003). Speakers are slower to name the ink color of an incongruent color-word combination (e.g., the word green in red ink, say "red") than of a series of Xs. Although competition is widely regarded in the cognitive neurosciences as a ubiquitous mechanism, its role in lexical selection has been disputed by proponents of a responseexclusion account. This account holds that words are selected upon exceeding an activation threshold, regardless of the levels of activation of other words, and that Stroop interference arises later in an articulatory buffer (e.g., Finkbeiner and Caramazza, 2006).

Whereas the lexical competition and response-exclusion accounts both explain the Stroop interference effect, Mahon et al. (2012) recently argued that associative facilitation from color-related words in the Stroop task (e.g., naming the ink color red is faster with fire than with lawn as the word stimulus) supports the response-exclusion account and challenges the competition account. They stated:

"An overlooked finding (Dalrymple-Alford, 1972) resolves the issue by changing the printed words to fire and lawn. According to the model of selection by competition, fire will compete more for saying the word "red" than will lawn, and thus should lead to slower naming latencies. ... The finding, originally reported by Dalrymple-Alford (1972), shows that naming latencies are faster with fire as the distractor than with lawn as the distractor. Glaser and Glaser (1989) replicated the effect, although did not test the zero Stimulus Onset Asynchrony (SOA) condition. We have replicated the original experiment from Dalrymple-Alford (1972) with our own materials and obtained the same pattern" (p. 365).

However, unlike what Mahon et al. (2012) suggest, the study by Dalrymple-Alford (1972) has not been overlooked by proponents of the lexical competition account. In particular, Roelofs (2003) applied the competition account to the Stroop task and discussed both the findings of Dalrymple-Alford (1972) and Glaser and Glaser (1989). Moreover, results of computer simulations of the study of Glaser and Glaser (1989) were presented to demonstrate that selection by competition explains the associative facilitation from color-related words (e.g., naming the color red was faster with fire than with lawn as word stimulus) as well as the time course of the facilitation effect. The simulations reported by Roelofs (2003) used WEAVER++, which is the computationally implemented competition model that has been repeatedly criticized over the past several years by proponents of the responseexclusion account. Thus, contrary to what Mahon et al. (2012) claim, the competition account explains the associative facilitation effect. Moreover, different from what Mahon et al. (2012) state, Glaser and Glaser did test the zero SOA (Experiment 5; see Figure 4 and Table 6 in their article). Still, the replication of Mahon et al. (2012) is useful, because over the past few years, researchers have not been able to replicate several of the findings that have been taken as evidence for the response-exclusion account (Lee and de Zubicaray, 2010; Mädebach et al., 2011; see Piai et al., 2011, 2012a, and Roelofs et al., 2012, for extensive discussions).

In naming color rectangles, Glaser and Glaser (1989) obtained an associative facilitation effect of $27 \mathrm{msec}$ or more when the distractor words were pre-exposed (e.g., by 100, 200,

\footnotetext{
* Corresponding author. Radboud University Nijmegen, Donders Institute for Brain, Cognition and Behaviour, Centre for Cognition, Spinoza Building B.01.08, Montessorilaan 3, 6525 HR Nijmegen, The Netherlands.

E-mail address: a.roelofs@donders.ru.nl (A. Roelofs). 
or $300 \mathrm{msec}$ ) and a facilitation effect of $13 \mathrm{msec}$ at zero SOA (i.e., $\mathrm{SOA}=0 \mathrm{msec}$ ). In the WEAVER ++ simulations run by Roelofs (2003), facilitation of $41 \mathrm{msec}$ or more was obtained at preexposure SOAs and no effect at zero SOA. We explored the performance of the model at zero SOA in new computer simulations to examine whether the absence of facilitation at this SOA is a robust property of the model or whether facilitation may arise when slightly varying a free parameter in the model (see Roelofs, 2003, for an extensive discussion of the parameter space). The simulations revealed that when the response-selection threshold (i.e., the critical difference in activation between target and competitors) in the model is increased somewhat (from 1.6 to 3.6), an associative facilitation effect of $27 \mathrm{msec}$ is obtained at zero SOA. This corresponds well to the $19 \mathrm{msec}$ facilitation obtained by Mahon et al. (2012). Thus, a competition model like WEAVER++ does not only explain the associative facilitation obtained at zero SOA by Dalrymple-Alford (1972) and Mahon et al. (2012), but also the time course of the associative facilitation observed by Glaser and Glaser (1989). This refutes the claim of Mahon et al. (2012) that "the phenomenon can be explained only if one dispenses with the idea of competitive lexical selection" (p. 375).

The critical difference parameter in WEAVER ++ concerns the response criterion in the model, which cognitively represents how much evidence for a particular response is required before it is selected. It has long been assumed that the response criterion is a fundamental parameter in determining response times (e.g., Luce, 1986). In the WEAVER++ simulations reported over the past several years, it has been the primary parameter allowed to vary (usually its value has been between 1.0 and 3.6) to accommodate differences in the magnitude of distractor effects among similar studies, presumably partly arising because of differences in materials, languages, or participants, among other factors. For example, whereas the magnitude of the associative facilitation effect observed by Dalrymple-Alford (1972) was $85 \mathrm{msec}$, it was only $19 \mathrm{msec}$ in the experiment of Mahon et al. (2012) and $13 \mathrm{msec}$ (at zero SOA) in Glaser and Glaser (1989). As shown in Roelofs (2003, Figure 14), increasing the critical difference parameter in WEAVER ++ (cognitively representing a more conservative response criterion) increases the magnitude of the distractor effects somewhat while preserving the direction of the effects (i.e., interference remains interference and facilitation remains facilitation). A more conservative response criterion implies that more evidence needs to be accumulated before a response is selected, which gives more room to interference and facilitation effects. Increasing the critical difference from 1.6 to 3.6 yielded associative facilitation at zero SOA in the model while preserving the original patterns of effects. That is, associative facilitation was still obtained at distractorpreexposure SOAs, and also the classic Stroop interference and facilitation effects from incongruent and congruent colorword combinations were preserved in the model.

The WEAVER ++ model explains the associative facilitation in the Stroop task by assuming that selection by competition is restricted to the set of color words, such as red, green, and blue. Consequently, with green in red ink, the responses red and green will compete. In contrast, with fire in red ink, the target response red is primed, whereas with lawn in red, the competitor green is primed. This difference in target and competitor priming yields the associative facilitation effect in the model. The assumption that selection by competition is restricted to the set of color words is similar to the assumption of the response-exclusion account that an incongruent colorword distractor yields interference "because the distractor satisfies the response relevant criteria (it is a color name in a color naming task)" (Mahon et al., 2012, p. 375). However, a major difference between the competition and responseexclusion accounts is that the criterion of response set membership operates during lexical selection in the competition account, but at the level of the articulatory buffer in the response-exclusion account.

In the Stroop task, there are only a few responses (typically three or four, like in the experiments of Dalrymple-Alford, 1972, and Glaser and Glaser, 1989, or six in the experiment of Mahon et al., 2012), which are repeated numerous times. This explains why a major part of the interference caused by incongruent distractor words is specific to the members of the response set (see Lamers et al., 2010, for a recent discussion). The role of the response set in determining semantic interference in the picture-word analog of the Stroop task seems to depend on various factors, including the number of responses and repetitions in an experiment (see Piai et al., 2012a, and Roelofs, 2001, 2008, for discussion). Semantic interference refers to the finding that picture naming is slower with distractors from the same semantic category (e.g., say "dog" to a picture of a dog combined with the distractor word cat) than with unrelated distractors (e.g., the word chair).

A critical difference between the competition and responseexclusion accounts of distractor interference concerns the time course of the effect. The response-exclusion account maintains that interference arises close to articulation onset, when a response to the distractor word is removed from the articulatory buffer. In contrast, the competition account maintains that interference arises during lexical selection, much closer to target presentation onset. According to an influential estimate of the onsets of word planning stages (e.g., Indefrey, 2011), lexical selection starts around 200-250 msec after color or picture onset and lasts until about $350 \mathrm{msec}$ post-stimulus onset, whereas the articulatory buffer is reached no earlier than about $145 \mathrm{msec}$ before articulation onset. In an event-related potential (ERP) study of picture-word interference, Piai et al. (2012b) obtained evidence that brain activity reflected the interference between about 230 and $370 \mathrm{msec}$ after picture onset, which corresponds to the estimated time window for lexical selection (Indefrey, 2011). The corresponding mean naming time was around $800 \mathrm{msec}$, which implies that the onset of the effect was about 570 msec before articulation onset. This is much earlier than predicted by the response-exclusion account (i.e., 145 msec before articulation onset).

To conclude, Mahon et al. (2012) maintain that associative facilitation in the Stroop task supports the response-exclusion account and challenges the lexical competition account. Here, we demonstrated that the empirical observation taken to be in favor of the response-exclusion account is, in fact, not only consistent with that account but equally compatible with the lexical competition account, as demonstrated by the results of WEAVER ++ simulations reported by Roelofs (2003) and in the present article. The competition account is specifically 
supported by ERP evidence on the time course of interference from distractor words.

\section{R E F E R E N C E S}

Dalrymple-Alford EC. Associative facilitation and interference in the Stroop color-word task. Perception and Psychophysics, 11(4): 274-276, 1972.

Finkbeiner M and Caramazza A. Now you see it, now you don't: On turning semantic interference into facilitation in a Strooplike task. Cortex, 42(6): 790-796, 2006.

Glaser WR and Glaser MO. Context effects in Stroop-like word and picture processing. Journal of Experimental Psychology: General, 118(1): 13-42, 1989.

Indefrey P. The spatial and temporal signatures of word production components: A critical update. Frontiers in Psychology, 2: 255, 2011.

Lamers M, Roelofs A, and Rabeling-Keus I. Selective attention and response set in the Stroop task. Memory \& Cognition, 38(7): 893-904, 2010.

Lee MM and de Zubicaray G. Lexical Selection is by Competition: A Failure to Replicate Mahon et al.'s (2007) Experiment 7. Poster presented to the 6th International Workshop on Language Production, Edinburgh, Scotland.

Luce RD. Response Times: Their Role in Inferring Elementary Mental Organization. New York: Oxford University Press, 1986.

Levelt WJM, Roelofs A, and Meyer AS. A theory of lexical access in speech production. Behavioral and Brain Sciences, 22(1): 1-38, 1999.

Mädebach A, Oppermann F, Hantsch A, Curda C, and Jescheniak JD. Is there semantic interference in delayed naming? Journal of Experimental Psychology: Learning, Memory, and Cognition, 37(2): 522-538, 2011.
Mahon BZ, Garcea FE, and Navarrete E. Picture-word interference and the response-exclusion hypothesis: A response to Mulatti and Coltheart. Cortex, 48(3): 373-377, 2012.

Piai V, Roelofs A, and Schriefers H. Semantic interference in immediate and delayed naming and reading: Attention and task decisions. Journal of Memory and Language, 64(4): 404-423, 2011.

Piai V, Roelofs A, and Schriefers H. Distractor strength and selective attention in picture naming performance. Memory \& Cognition, 40(4): 614-627, 2012a.

Piai V, Roelofs A, and Van der Meij R. Event-related potentials and oscillatory brain responses associated with semantic and Stroop-like interference effects in overt naming. Brain Research, 1450: 87-101, 2012b.

Roelofs A. Set size and repetition matter: Comment on Caramazza and Costa (2000). Cognition, 80(3): 283-290, 2001.

Roelofs A. Goal-referenced selection of verbal action: Modeling attentional control in the Stroop task. Psychological Review, 110(1): 88-125, 2003.

Roelofs A. Dynamics of the attentional control of word retrieval: Analyses of response time distributions. Journal of Experimental Psychology: General, 137(2): 303-323, 2008.

Roelofs A, Piai V, and Schriefers H. Context effects and selective attention in picture naming and word reading: Competition versus response exclusion. Language and Cognitive Processes, 2012.

Received 4 December 2012 Reviewed 9 January 2013 Revised 14 January 2013 Accepted 7 March 2013 Action editor Sarah MacPherson Published online 21 March 2013 